\title{
A Study on How to Activate the Gangneung Danoje's Cultural Contents
}

\section{강릉 단오제의 문화 콘텐츠 할성화 방안 연구}

\author{
Kyung Suk Yoo ${ }^{1}$
}

유경숙 1

${ }^{1}$ Director, Content planning, World Festival Research Institute, Korea, prniki1220@naver.com

\begin{abstract}
This study was initiated from a concern to enhance the attractiveness of the most fundamental festival contents in reinforcing the global competitiveness of Gangneung Danoje, registered as an intangible cultural heritage of humanity by UNESCO. A total of 11 experts, including domestic and international festival experts, parade experts, PR experts, performance experts, etc., stay at the Gangneung danoje site for an average of 27 hours, observe the representative programs and surrounding programs evenly, and examine the diagnosis and improvement points based on the expertise of each field. Representatively, it emphasized the possibility of future development of parade, suggested the reduction of the parade and balanced use of urban space, and emphasized various approaches with new perspectives for a leap forward as a global festival. In addition, there are audiences who have a sense of disparity for danogut because of their religious nature, but this is a folk belief that was the basis of their ancestors' lives, so they should not lose their core value, but rather suggested a modern expression method that modern people can sympathize with. The regional characteristics of Gangneung Danoje were cited as as the biggest strength. On the other hand, the low artistic perfection as a disappointment. Hope that this study will help to strengthen the global competitiveness of Gangneung danoje in the future.
\end{abstract}

Keywords: Culture of Dano, Gangneung Danoje, Festival, Parade, UNESCO

요약: 본 연구는 유네스코 인류무형문화유산에 등재된 강릉 단오제의 글로벌 경쟁력을 강화하는데 있어 가장 근본적인 축제 콘텐츠의 매력도를 높이고자 하는 고민에서 시작되었다. 국내외의 축제 전문가, 퍼레이드 전문가, $\mathrm{PR}$ 전문가, 공연 전문가 등 모두 11 명의 전문가가 평균 27시간 동안 강릉 단오제 현장에 머물며 대표프로그램 및 주변 프로그램을 골고루 관람하고 분야별 전문성을 기반으로 한 진단 및 개선점을 3 차에 걸쳐 도출하였다. 대표적으로 신통대길 길놀이에 대한 향후 발전 가능성을 강조하였으며 퍼레이드 동선 축소와 도심 공간 균형적 활용을 제시하였고 향후 글로벌축제로의 도약을 위해 새로운 시각을 가미한 다양한 접근을 강조하였다. 또한 단오굿에 대해 종교성을 이유로 이질감을 갖는 관객이 있으나, 이는 조상들의 삶의 기반이었던 토속신앙으로써 강릉 단오제의 핵심 가치임을 잊지 말아야 하며 오히려 현대인들이 공감할 수 있는 현대적 표현법을 제안하였다. 강릉단오제가 갖는 지역적 특색을 최대강점으로 꼽는 반면 예술적 완성도를 가장 아쉬운 점으로 꼽았다. 본 연구가 향후 강릉 단오제의 글로벌 경쟁력 강화에 조금이나마 도움이 되기를 기대해 본다.

Received: June 04, 2021; $1^{\text {st }}$ Review Result: July 22, 2021; $2^{\text {nd }}$ Review Result: September 06, 2021 
핵심어: 단오문화, 강릉 단오제, 페스티벌, 퍼레이드, 유네스코

\section{1. 서론}

코로나19 장기화에 따른 경기침체, 대규모 집합 행사 금지, 사회적 거리 두기 등의 조치로 국내 대부분의 축제와 대형 문화행사들이 힘든 시기를 보내고 있다. 2020년 상반기, 코로나 19 를 갑작스럽게 겪게 돼 지역 축제들은 국가적 안전조치 시행과 지역민의 건강을 위해 사실상 일방적으로 축제 취소 결정이 될 수밖에 없었고 하반기에 개최되는 축제들은 그나마 자체적으로 합리적 판단을 통해 일부 축소 또는 온라인으로 운영되는 상황을 맞이하게 되었다.

코로나19 2년째를 맞는 2021년에는 전국의 축제 운영 실무자들이 운영 방식에 대한 고민이 활발해지면서 비대면 또는 온라인 축제를 개최하고 예산대비 효율적 온라인 축제 프로그램 운영, 규모는 작아졌지만, 순발력이 돋보이는 야외 비대면 프로그램, 현장에 가지 않아도 가정에서 축제를 즐길 수 있는 키트 참여방식 등 다양한 축제 개최 방식을 선보이고 있다.

그 중, 천년 역사를 가진 강릉 단오제(江陵端午祭)의 경우는 전통적으로 4 5월 한 해 농사의 시작인 모내기를 마치고 마을의 안녕과 풍년, 풍어를 기원하는 제의적 행사로 6월에 개최되는 가장 큰 축제 중의 하나다[1]. 가을에 집중된 대형 축제들에 비해 상대적으로 이르게 진행되는 국가적 축제라 할 수 있다. 그만큼 타 축제에 비해 개최 방식에 대한 고민이 클 뿐만 아니라, 중요무형문화재 제13호, 유네스코 인류 무형문화유산에 등재된 우리나라의 대표적 축제로써 단순히 비대면 방식으로의 전환이 아닌 글로벌 축제로서의 내실 있는 콘텐츠 업그레이드를 위해 노력을 기울이고 있는 실정이다[2][3].

본 연구에서는 코로나19 장기화로 어려움을 겪고 있는 시기에 상대적으로 온라인과 오프라인을 병행하며 취소보다는 축소 또는 온라인 축제 개최를 순발력 있게 진행해 온 강릉 단오제를 중심으로 글로벌시장에서 돋보일 수 있는 축제 콘텐츠 개선 및 활성화 방안에 관해 집중적으로 살펴보고자 한다.

단오(端午)는 예로부터 우리나라의 4대 명절 중 하나로 1 년 중 만물을 풍성하게 하는 양기가 가장 성한 날로 음력 5월 5일(초닷새)에 지내던 대표적인 명절이다. 단오 문화의 유래와 관련하여서는 중국 초나라의 굴원이 억울한 모함에 시달리다 멱라수에 투신자살하였는데 굴원의 억울함을 달래주기 위해 제를 지내던 데서 시작돼 우리나라에까지 전해진 것으로 알려져 있다. 또한 그 이전에도 '악월악일'이라 하여 설의 영향을 받아 나쁜 기운을 막고 사람들의 건강을 기원하는 의식으로 내려오다 굴원이라는 영웅 스토리와 접목된 것으로 보고 있다[4].

그러나 우리나라의 단오는 근본적으로 농경사회를 바탕으로 한 절기 초하(初夏)에 맞춰 기풍제의 개념으로 지내오고 있으며 풍년을 기원하는 대추나무 시집 보내기, 마을 사람들의 건강과 안녕을 기원하는 창포 놀이, 대관령서낭을 모시는 토속 신앙적 절차, 지역의 화합과 협동을 강조하는 신주미 의식 등 우리나라만의 전통 문화와 의식에 충실한 축제로 굴원의 스토리와는 공통점을 찾아보기 어렵다.

오늘날 강릉 단오제는 강릉 시민 1,000 여명이 참여하는 연산홍 챌린지, 강릉지역의 구수한 사투리를 짧은 극으로 만들어 선보이는 사투리 경연대회, 단오를 상징하는 
수리취떡과 신주미를 가정집으로 직접 배달해주는 배달의 단오, 21 개 읍면동 주민들이 직접 참여하는 길놀이 퍼레이드, 단옷날 즐기는 탈과 창포 등을 놀이를 통해 참여할 수 있는 단오 키트 등 현대인의 라이프스타일과 사회적 여건을 감안한 프로그램들이 선보이고 있다.

그럼에도 불구하고 지금과 같은 침체기가 계속될 경우, 국내에서의 브랜드 구축 과정에 심각한 영향을 초래할 뿐만 아니라 글로벌 시장에서 유네스코 인류 무형문화유산으로서의 위상을 높이기 위한 발전적 연구가 더욱 필요한 시점이라 할 수 있다. 이러한 시기적, 환경적 여건을 고려하여 강릉 단오제의 영역별 콘텐츠 구성, 공간 활용, 종교적 성격의 콘텐츠 활용 방안, 프로그램을 통한 일관성 있는 구성 등 글로벌 축제로서의 콘텐츠 업그레이드를 위한 심층 연구의 필요성이 제기된다.

\section{2. 선행연구의 검토}

\section{1 강릉 단오제 관련 선행연구}

그동안 우리나라에 전해 내려오는 단오 풍습과 축제의 형태로 보존하고 있는 강릉 단오제와 관련한 연구는 비교적 활발하게 진행되어 왔다. 2000년대 이후 단오 풍습과 관련한 각종 단행본과 어린이 서적을 제외하고도 관련 연구논문만 190 여 편에 이르며 특히 2005년 강릉 단오제가 중국을 제치고 유네스코 인류무형문화유산에 등재된 이후에 10 여 년간 관련 연구가 집중된 것을 알 수 있으며 최근 들어 학술적 연구와 외부적 관심이 상대적으로 약해진 상태라 볼 수 있다.

2000년대 이후 가장 많이 진행된 연구는 단오와 관련한 구비문학 그중에서도 주신 격인 범일 국사, 여서낭 신화 등 단오 설화와 연관된 연구가 주를 이루고 있다. 강릉 단오제와 관련한 주신 교체와 문제점에 대한 역사학적 연구가 다수 등장하였고[5][6], 축제 참가자들을 대상으로 정량 조사를 통한 참가 동기 및 만족도 분석, 재방문 의사에 미치는 영향 연구가 가장 많이 다뤄진 것을 알 수 있다[7].

비교적 최근에 이루어진 연구에서 몇 가지 흥미로운 내용을 살펴보자면 다음과 같다. 오훈성은 로제 카이와의 놀이 이론을 적용한 강릉 단오제의 분석: 미미크리와 일링크스를 중심으로 한 연구에서 로제 카이와의 놀이 이론에 따르면 축제의 기원은 결국 가면과 홀림 다시 말하면 미미크리(mimicry, 모의)와 일링크스(illinx, 현기증)로 점철될 수 있는데 오늘날의 축제에서도 결국 카이와가 주장하는 놀이적 요소를 제외하면 축제의 본질적 기능을 할 수 없다는 것이다. 이와 관련하여 강릉 단오제의 다양한 프로그램들을 미미크리와 일링크스적 요소로 구분하면서 프로그램별 특성과 개선해야 할 사항들을 제시하였다[8].

강릉 단오제의 역사적 신앙성과 주신(主神)의 변화과정을 연구한 박도식은 강릉 단오제의 주신 교체의 시기와 역사적 배경에서 주신의 교체 시기를 300 400년 전으로 추정하는 과정을 밝히고 있다. 1603년 허균 선생이 강릉 단오제를 구경했다는 기록이 남겨진 당시에는 강릉 단오제가 김유신 장군을 주신으로 모시고 있었으나 1762년에는 주신이 범일 국사로 바뀌어 있었고 이를 기반으로 재구성해보면 김유신장군에서 범일 국사로 주신이 교체된 시기는 선조 36년인 1603년에서 영조 시대인 1762년 사이에 이루어졌을 것으로 추정한다고 밝혔다[9].

임영화는 강릉 단오제(汇陵端午祭)와 중국 단오절(端午节)에 대한 비교연구에서 유네스코 인류무형문화유산에 등재된 한국과 중국의 단오 문화 차이를 규명하였는데 
우리나라의 단오는 샤머니즘 의식과 농부들의 음악과 풍습 등 예술성이 가미된 무형 문화유산은 물론 그네뛰기, 창포물에 머리를 감는 토속적 풍습, 지역적 식문화가 가미된 떡 문화 등이 특징이며 신을 위한 의식, 토속 신앙적 제의에 초점이 맞춰져 있다고 봤다. 반면 중국의 단오는 'Duanwu'라고 발음하는데 지역적 환경적 관습을 바탕으로 역사적 인물을 기리는 행사 또는 축제를 벌이는 풍습으로 전해지고 있다고 봤다[10].

이 밖에도 강릉 단오제와 관련한 연구는 꾸준히 이어져오고 있으나, 앞에서 언급한 바와 같이 유네스코 인류무형문화유산에 등재된 이후 학술적 연구와 관심이 집중적으로 이루어지다 최근에는 관심이 미약해진 상태라 할 수 있다.

\section{3. 연구문제 및 방법}

\section{1 연구문제}

본 연구는 강릉 단오제의 2005년 유네스코 인류무형문화유산 등재 이후 주를 이루었던 주신(主神) 관련 연구, 축제 방문객 분석, 재방문 의사 분석 등의 주요 영역을 벗어나 글로벌 축제로서 우뚝 설 수 있는 콘텐츠 매력도를 개선하기 위한 고민에서 시작되었다. 천년을 이어온 우리나라의 대표적 축제로서 현재까지 명맥을 이어오고 있으나 현대인의 라이프스타일, 브랜드 파급 정도, 콘텐츠 매력도 등 시간이 흐를수록 개선이 필요한 부분이 부각되고 있어 향후 글로벌 시장에서 한국의 대표 축제로 자리매김할 수 있도록 가장 핵심적인 콘텐츠 분석 및 개선방안을 모색해보고자 하였다.

때문에 참가자들의 반응보다는 콘텐츠 구성과 재현, 난장, 공간 구성 등 축제 프로그램 전반에 걸쳐 전문가적 진단을 시행하는 것이 시급한 과제라 판단하였다. 이를 위해 다음과 같은 연구 문제를 설정하고자 한다.

신통대길 길놀이(퍼레이드), 난장, 공연물, 먹거리 서비스, 체험프로그램, 홍보 등 현재 강릉 단오제에서 시행되고 있는 프로그램의 특성과 한계점은 무엇인가?

강릉 단오제가 글로벌 시장에서 경쟁력을 갖추기 위해서는 향후 어떠한 프로그램의 보완 및 개선이 필요할 것인가?

\section{2 연구방법}

강릉 단오제의 글로벌 축제로서의 경쟁력을 갖추기 위한 콘텐츠 진단 및 개선방안을 살펴보기 위한 본 연구는 현재까지 매년 소개되고 있는 대표 프로그램 및 보조 프로그램을 대상으로 진행하고자 한다. 다만, 현재 코로나19로 온라인과 오프라인 프로그램이 병행되고 있으며 상당 부분 축소 또는 임시 변경된 부분이 있는 만큼 코로나 발생 직전의 프로그램을 대상으로 시행하였다.

본 연구에서는 최근 3 년 이내 강릉 단오제 현장을 1 회 이상 직접 참여하고 관람한 경험이 있는 국내외 축제 전문가, 홍보마케팅 전문가, 퍼레이드 전문가, 공연전문가를 대상으로 심층 인터뷰(FGI) 방식으로 진행하였다.

질적 연구의 대표적 방식인 포커스 그룹 인터뷰(FGI, Focused Group Interview)는 연구 주제와 콘텐츠 이해도가 높은 전문가그룹을 직접 만나 집단심층면접을 통해 진행하였는데 강릉 단오제에서 선보이고 있는 프로그램과 공간활용, 신통대길 길놀이 등에 대한 문제점과 특징, 장단점을 먼저 살펴보고 이에 대한 미래가치와 활성화 방향을 
구체적으로 논의하였다.

본 연구의 응답자는 국내외 분야별 전문가 11 명을 선정하고 1 차적으로 강릉 단오제를 직접 참관하여 최근의 축제 현황을 방문객 입장에서 자유롭게 체험하도록 유도하였다. 2 차로는 강릉 단오제의 현황과 문제점 등을 설명한 후 집단심층면접을 통해 공통의 문제점과 현실적 한계, 관객 현황 등을 공유하고 전문 분야별 질문을 던져 분야별 의견과 진단 결과를 진술하도록 유도하였다. 3차 심층 인터뷰 단계에서는 2 차 집단 인터뷰 과정에서 나왔던 내용 중 대표적인 문제점과 원인, 해결방안, 더욱 상세한 의견을 확인해야 할 사항 등을 파악하여 개별 심층 면접으로 시행하였다.

\section{4. 연구결과}

11 명의 전문가 그룹 응답자를 대상으로 한 강릉 단오제의 콘텐츠 분석결과, 핵심적인 부분을 요약하자면 강릉 단오제의 글로벌 축제 잠재성, 향후 집중 개발해야 할 킬러 콘텐츠, 퍼레이드 실행의 문제점, 콘텐츠 구성 비율 등이 제시되었다.

먼저, 강릉 단오제가 세계적 축제로 거듭나기 위해서 예술성, 지역성, 국제성, 축제성, 대중성 5 가지 요소를 중심으로 평가한 질문에서는 강릉 단오제의 지역적 색채를 가장 큰 장점으로 선정하였고 그 뒤로 축제성과 대중성을 뽑았다. 반면, 강릉 단오제에서 선보이는 전반적인 프로그램에 대한 예술적 완성도가 가장 부족한 약점으로 드러나 이에 대한 시급한 보완이 필요할 것으로 보인다.

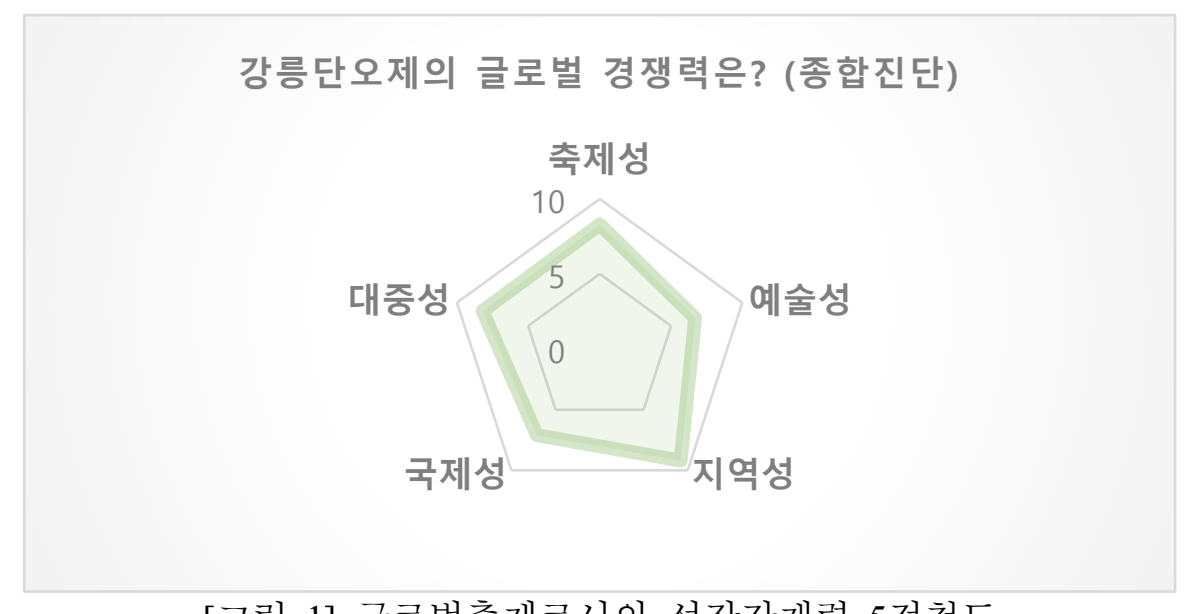

[그림 1] 글로벌축제로서의 성장잠재력 5점척도

[Fig. 1] 5-point Scale of Growth Potential as a Global Festival

강릉 단오제가 갖고 있는 유무형의 가치와 프로그램을 종합적으로 살펴볼 때 지속적으로 이어가야 할 핵심 자산(강점)에 대한 질문에서는 수백년동안 이어져온 시민들의 축제에 대한 애정과 관습적 행위(시민에 의한 축제), 강릉시민들의 역사와 추억이 담긴 공유 공간인 남대천, 토속신앙이자 강릉 단오제의 핵심콘텐츠인 제사의식(단오굿), 유네스코 인류무형문화유산에 등재되었다는 브랜드, 축제의 본질을 이어가는 난장, 강릉의 지역성이 묻어있는 단오 정신을 핵심포인트로 꼽았다. 


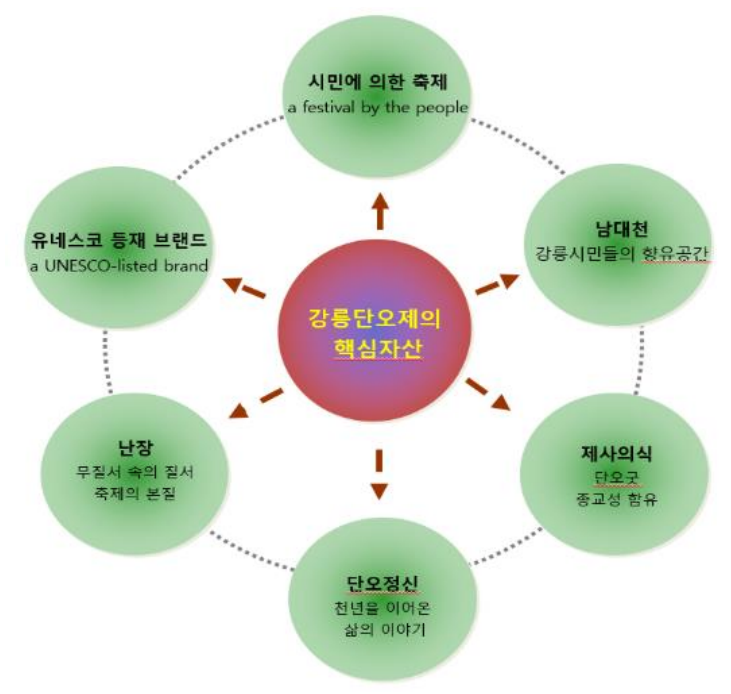

[그림 2] 강릉 단오제가 가진 핵심 자산(강점)

[Fig. 2] Core Assets of Gangneung Danoje (Strengths)

또한 강릉 단오제의 가장 흥미로운 프로그램이자 향후 킬러콘텐츠로 육성할 콘텐츠로는 10 년 전부터 강릉시의 21 개 읍면동 시민들이 직접 참여하여 선보이고 있는 신통대길 길놀이(퍼레이드)가 11 명 응답자 전원이 1 위로 선정하였고 뒤를 이어 관노가면극과 학산오독떼기 공연, 단오굿, 사전행사이자 나눔의 상징인 신주 빚기(술과 떡 나눔), 단오의 대표적 민속놀이인 씨름과 그네, 창포 감기, 사물놀이 경연대회, 강릉 사투리 경연대회가 순서대로 선정되었다. 단오의 상징인 난전은 역사와 명분은 매우 우수하나 이미 전통적 모습이 완전히 훼손돼 발전 가능성에서 좋은 점수를 얻지는 못하였다.

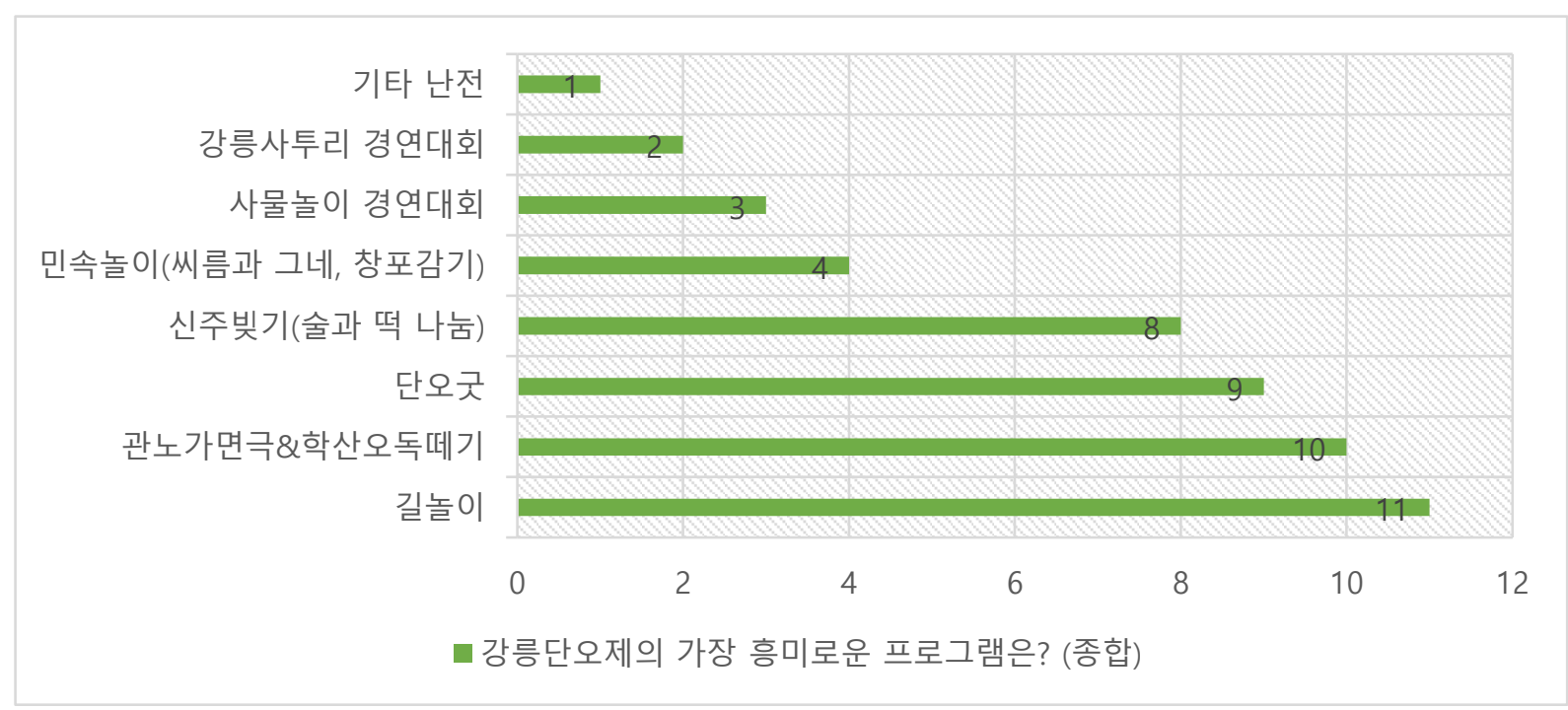

[그림 3] 킬러콘텐츠로 성장시킬 대표 콘텐츠

[Fig. 3] Representative Contents to Grow into Killer Contents 
강릉 단오제의 공간 활용에 대해서는 다수의 전문가가 가장 시급한 개선 필요성을 강조하였다. 현재의 강릉 단오제는 남대천을 중심으로 단오장이 양쪽으로 펼쳐지는데 외부 방문객 입장에서는 강릉역, 터미널에 도착해도 천년을 이어온 축제 개최도시임을 전혀 인지할 수 없는 점을 지적하였다. 때문에 남대천 중심의 축제 장을 강릉 시내 곳곳을 넓게 활용하는 방안을 제시하였고 난장 규모는 줄이며 단오의 핵심 주제인 단오 풍습 및 체험프로그램을 중앙으로 배치할 것을 제안하였다. 또한 수심이 낮은 남대천을 보다 적극적으로 활용하여 시민들의 향유공간임을 축제에서 인지할 수 있도록 식당 부스들을 재배치할 것을 권하였다. 현재는 식당 부스들이 남대천을 가로막는 병풍 역할을 해 사람들의 눈높이에서는 남대천을 전혀 볼 수 없는 상황이다.

천년을 이어온 강릉 단오제의 핵심콘텐츠이자 축제 실무자들에게 가장 큰 고민거리를 안겨주고 있는 단오굿과 관련하여서는 시대적으로 부정적 여론은 앞으로도 얼마든지 있을 수 있는 자연스러운 현상이니 개의치 말고 반드시 지속, 개발할 것을 제안하였다. 현재 강릉 단오제의 메인 무대에는 축제 기간 동안 20 여 가지의 다양한 굿이 릴레이로 펼쳐지는데 종교적인 측면에서 이를 부정하는 분위기가 적지 않다. 그러나 응답자들은 단오제의 정통성과 차별성, 제의성, 흥미성 측면에서 단 한 명도 예외없이 단오굿은 반드시 이어가야 할 핵심적 가치라는데에 이견이 없었으며 오히려 굿에 대한 현대적 재해석, 코로나 19 와 같은 시의적 이슈와 매칭하여 전 국민적 염원과 건강을 기원하는 민속 신앙의 보존 차원에서 보존, 확장할 것을 주문하였다.

신통대길 길놀이(퍼레이드)의 경우 모든 응답자가 가장 강력한 킬러 콘텐츠 후보로 손꼽았으나 현재의 콘텐츠 구성이나 표현력, 예술적 완성도 측면에서는 향후 보완해야 할 점이 매우 많은 것으로 응답하였다. 시급히 개선해야 할 점들을 몇 가지 언급하자면 퍼레이드 동선이 지나치게 길어 축제의 분위기가 지속되지 못하는 단점이 있어 현재의 동선을 3 분위 1 가량 축소하는 방안을 제시하였다. 또한 전체 퍼레이드 구간에서 콘텐츠 노출도가 균형적이지 못하고 파이널 스테이지인 남산교에만 집중되어 있어 이 또한 퍼레이드의 기능이 편중되는 것으로 시급히 개선해야 하는 점으로 꼽혔다.

또한 퍼레이드에 참여하는 강릉시의 21 개 읍면동은 마을별로 개별 콘텐츠를 준비하여 퍼레이드에 참여하는데 마을 대항전 분위기보다는 퍼레이드의 전체적 스토리를 입혀 하나의 거대한 콘텐츠로서 완성도를 높이는 노력이 필요하다고 하였다. 전체를 아우르는 스토리 구성없이 마을별로 분리되어 등장하기 때문에 현재는 중간중간 맥이 끊기는 경우도 수시로 발생할 뿐만 아니라 관람객이 신통대길 길놀이의 재미를 온전히 느끼기에는 다소 산만하게 느껴질 수밖에 없다.

예를들면 벨기에의 성혈의 행렬(procession of the holy blood) 축제는 강릉단오제보다 조금 늦은 2009년에 유네스코 인류무형문화유산에 등재된 퍼레이드형 전통축제로 과거 십자군 전쟁 당시 예수의 혈흔이 담긴 옷을 기리는 데서 시작한 축제다. 이 축제에서는 1,500 여 명의 시민들이 제각기 재현하고 싶은 모든 내용을 담기 어려워 성경 속에 나오는 27 가지 대표적인 에피소드를 추려 퍼레이드의 핵심 스토리로 활용하는 구조다. 이와 같이 강릉단오제의 경우에도 상징성을 가지면서 전체를 관통하는 핵심 스토리를 구축하여 세부 표현을 보완하는 노력을 기울일 필요가 있다고 지적하였다.

의외의 연구결과도 나타났다. 연구에 참여한 전문가 그룹은 대부분 국내외의 축제 경험이 많고 축제 관객에 대한 이해도가 높은 응답자들이며 1 명은 현재 프랑스에서 활동중인 아트디렉터였는데 응답한 국내외 전문가 모두 강릉 단오제를 찾는 현장 방문객이 상대적으로 매우 젊다는 의견을 제시하였다. 이는 단오 문화가 강릉지역 
노년층만의 전유물이 아니라 가족 단위 방문객들에게 흥미를 끌 수 있는 요소가 많을 뿐만 아니라 향후에도 단오의 현대적 구현이 매우 중요한 방향이라고 할 수 있다.

< 신통대길 길놀이의 콘텐츠 구성방안 (예시) >

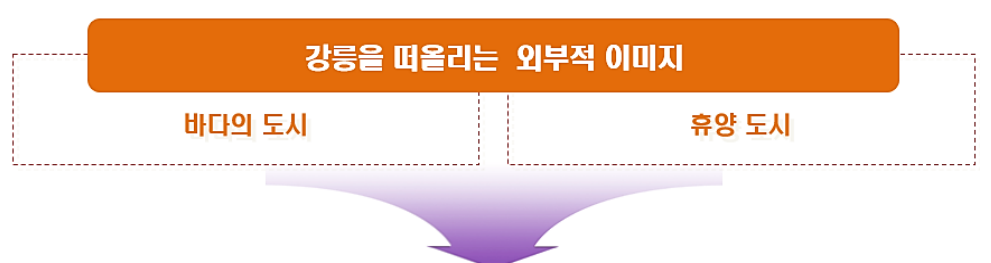

현재, 신퉁 매길 갤놀이의 특징

21 개 읍 · 면 · 동 시민들이 열정적 참여하여 펼침

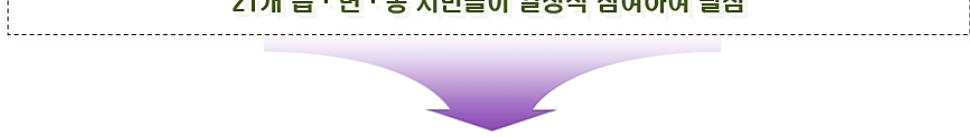

비롯되는 한계

(1) 주민 스스로 참여 $\rightarrow$ 의미 좋으나, 전문성 부족 $\rightarrow$ 볼거리 매력도 저하

(2) 기획과 표현의 한계 $\rightarrow$ 같은 내용 반복 등장 $\rightarrow$ 콘텐츠 완성도 하락

의미는 좋지만, 두 번 찾아올 정도는 아닌 시민 길놀이

\section{결론 : 퍼레이드 전체에 일관된 스토리 구조 삽입}

(1) 바다와 육지가 조화된 강릉이야기

(2) 강릉의 어로문화와 농경문화가 퍼레이드의 메인 스토리

[그림 4] 신통대길 길놀이의 콘텐츠 구성방안

[Fig. 4] Content Organization Plan of the Parade

이에 대해 강릉 단오제는 전통 명절을 축제화하고 미래의 천년을 이어가는 글로벌 축제로 성장하기 위해서는 전체 프로그램의 $50 \%$ 이상을 청년 프로그램으로 확대할 것을 제안하였다. 청년 프로그램이라고 하여 청년들만 참여하거나 청년들이 좋아하는 댄스 배틀, 맥락 없는 신기술 도입 등 주제와 상관없는 프로그램 도입을 의미하는 것이 아니라, 젊은 층이 이해할 수 있고 소비할 수 있는 단오의 현대적 재해석이 필요함을 강조하였다.

\section{5. 결론 및 시사점}

본 연구는 한국의 4대 명절이자 유네스코 인류무형문화유산에 등재된 강릉 단오제의 글로벌 경쟁력을 키우기 위한 축제 콘텐츠를 전문가적 시선에서 심층분석하고 그 방향성을 모색하기 위한 목적에서 시작되었다. 이를 위해 국내외 축제 전문가, 퍼레이드 전문가, 공연 전문가, 홍보마케팅 전문가 11 인이 참여하였으며 1 박 2 일 동안 강릉 단오제 및 강릉 시내를 골고루 관람한 뒤 분야별 전문성에 맞게 축제콘텐츠를 분석하고 관객의 동선과 참여 정도, 공간 활용 등을 고려하여 향후 발전 방향을 제시하였다. 
대표적으로 현재 시연 되고있는 강릉 단오제의 콘텐츠 중 10 여년 전부터 강릉시민들이 참여하여 선보이고 있는 신통대길 길놀이(퍼레이드)가 향후 축제의 대표콘텐츠로 집중할 만한 가능성 있는 콘텐츠로 꼽혔고 파이널 스테이지에 해당하는 남산교에만 지나치게 편중되어 도심 공간을 골고루 활용하지 못하고 있는 부분, 지나치게 긴 구간설정으로 축제성이 지속하지 못하는 점 등이 한계점으로 드러났다.

그뿐만 아니라 종교적 색채가 짙다 하여 외부 관람객에게 호불호가 나뉘고 있는 단오굿과 관련하여서는 특정 종교가 아닌 우리 조상들의 삶과 함께 했던 민속신앙인만큼 더욱더 가치를 보존하되 현대인들이 공감할 수 있는 시의적 메시지 활용과 현대적 해석으로 새로운 매력을 드러낼 수 있는 표현법을 강구할 필요가 있다 하였다.

또한 강릉 단오제의 글로벌 경쟁력(강점)으로는 강릉만이 가진 지역적 특색을 매우 잘 간직하고 있고 지역민들이 적극 참여하여 행해지는 축제의 관습적 행위가 가장 큰 매력 포인트로 꼽혔다. 반면 역사성과 시민참여 등은 매우 훌륭하나 실제로 현장에서 구현되는 콘텐츠들의 예술적 수준이 전반적으로 미흡하여 이를 시급히 보완해야 할 필요성이 제기되었다.

강릉 단오제가 지역 토착민을 중심으로 이어져 온 축제인 만큼 노년층의 의존도가 매우 높을 것으로 인식될 수 있으나, 의외로 젊은 층에도 매력적으로 다가가는 젊은 축제라는 의견이 다수 드러났다. 이는 단오 문화에 익숙하진 않지만 가족 단위 방문객들에게 강릉 단오제가 향후에도 더욱 매력적으로 소구될 수 있는 강점이 있음을 시사한다고 할 수 있다.

이와 같이 강릉 단오제의 글로벌 경쟁력을 키우기 위한 전문가 그룹의 콘텐츠 진단 및 발전 방안에 대한 연구는 몇 가지 장점과 활성화 방안으로 정리되었다. 연구가 진행되는 동안 전문가들이 자유롭게 축제 현장을 방문하고 전문분야가 달라 의견의 빈도가 분산된 한계점도 발견되었다. 향후에는 이와 같은 부분을 보완하여 보다 구체적인 장르별 적용 방법, 단오굿의 현대적 재해석과 방법론을 세분화하여 연구한다면 향후 강릉 단오제의 글로벌화, 내실 있는 축제 발전에 도움이 될 수 있을 것으로 기대한다.

\section{References}

[1] Shim oh sub, Kim ki sul, Park do sik, Gangneung danoje's Training manual : UNESCO lntangible cultural heritage of humanity, national intangible cultural property No.13, chae ryun, (2017)

[2] http://encykorea.aks.ac.kr/Contents/SearchNavi?keyword=ridx=0\&tot=8, Jun 04 (2021)

[3] An kwang seon, The changes of the chief deity in Gangneung Dano-je, Korean Journal of Folk Studies, (2017), No.41, pp.179-198 DOI: $10.35638 / \mathrm{kjfs} . .41 .201712 .007$

[4] Gang So Chun, Implications of korea's Gangneung dano festival to the transmission of Chinese dano culture, Dongyung, (2018), Vol.4, pp.13-38.

[5] Park do sik, The Period and the Historical Background of the Replacement of the Lord God in Gangneung Danoje Festival, Journal of Local History and Culture, (2019), Vol.22, No.1, pp.127-158. DOI : 10.23013/localh.2019.22.1.005

[6] Shim hyung june, A study on the replacement of main god in Gangneung-Dano festival(江陵端午祭): the issue on the appearance of Bumil Guksa(梵日國師), The Journal of Korean Historical-folklife, (2013), No.43, pp.259-298. UCI : G704-000849.2013..43.009

[7] Jeong ug yeong, Ji ke yung, Han jin young, Determinants of Gangneung Dano Participants` Satisfaction and Revisit Intention, International Journal of Tourism and Hospitality Research (IJTHR), (2015), Vol.29, No.6, pp.129-138. UCI : 
G704-001491.2015.29.6.001

[8] Oh hun sung, An analysis of Gangneung Danoje using Caillois' theory of play: Based on the properties of mimicry and ilinx, International Journal of Tourism and Hospitality Research (IJTHR), (2021), Vol.35, No.1, pp.5-20. DOI : 10.21298/IJTHR.2021.1.35.1.5

[9] Kim jeong nam, Background story of Gangneung-Dano festival(江陵端午祭) and Korean modern novels - -focusing on the adoption and transformation aspects of the motif, The Review of Korean Cultural Studies, (2015), Vol.49, No. 49, pp.367-392. DOI : 10.17329/kcbook.2015.49.49.013

[10] Lim yung wha, A Study on the Comparison between Gangneung Danoje and Dragon Boat Festival in China - Based on the UNESCO listing, Journal of China Studies, (2018), Vol.21, No.1, pp.203-221, DOI : 10.20288/JCS.2018.21.1.203 